\title{
LEITURA DE TEXTOS ORIGINAIS DE CIENTISTAS POR ESTUDANTES DO ENSINO SUPERIOR
}

\author{
The reading of original texts of scientists \\ by students in a university course
}

Marcelo Zanotello ${ }^{1}$

Resumo: Neste trabalho investigo os sentidos produzidos por alunos do primeiro ano, em um curso superior de ciência e tecnologia, a partir da leitura de textos originais de cientistas ilustres nos campos da termodinâmica e da teoria cinética dos gases. A análise é realizada com base nas respostas por escrito dos estudantes a um questionário proposto sobre os textos. A atividade desenvolvida se insere no contexto de uma reflexão sobre a inclusão de elementos de história da ciência em aulas de ciências nos diversos níveis de ensino. Apesar de certas dificuldades apontadas pelos alunos na leitura dos textos, que, do meu ponto de vista, constituem oportunidades de uma efetiva mediação dialógica em sala de aula, observa-se, em seus relatos, a enriquecedora contribuição que a presença da história da física proporcionou, por meio da leitura dos originais, tanto para a formação de uma cultura científica quanto para a compreensão de determinados conceitos.

Palavras-chave: História da ciência. Textos originais. Leitura. Produção de sentidos. Termodinâmica.

\begin{abstract}
In this paper, I analyze the production of meanings by first-year students on a university course of science and technology based on the reading of original texts of notable scientists in the fields of thermodynamics and the kinetic theory of gases. The analysis is performed on the written registers of the students' answers to a questionnaire on the proposed texts. The activity is developed in the context of a reflection about the inclusion of elements of the history of science in science classes at various levels of education. Despite some difficulties pointed out by students in the reading of texts, (which in my opinion is to provide opportunities for effective meditational dialogue in the classroom), they noted in their accounts the rich contribution that the presence of history of physics provided, through the reading of original texts, for the formation of a scientific culture and for the understanding of certain concepts.
\end{abstract}

Keywords: History of science. Original texts. Reading. Production of senses. Thermodynamics.

\footnotetext{
${ }^{1}$ Graduado em Licenciatura em Física, doutor em Engenharia Mecânica (Materiais e Processos). Docente, Centro de Ciências Naturais e Humanas, Universidade Federal do ABC (UFABC). Santo André, SP, Brasil. <marcelo.zanotello@ufabc.edu.br>
}

Centro de Ciências Naturais e Humanas, Universidade Federal do ABC (UFABC)

Rua Santa Adélia, 166

Santo André, SP

$09.210-170$

987

Ciência \&̊ Educação, v. 17, n. 4, p. 987-1013, 2011 


\section{Introdução}

Este trabalho destina-se a analisar possíveis contribuições da leitura de textos originais de cientistas por estudantes do primeiro ano de um curso Superior em ciência e tecnologia, em aulas de física básica, abordando temas selecionados em termodinâmica e teoria cinética dos gases. Quais sentidos seriam atribuídos, pelos alunos, aos textos lidos? Poderiam tais textos, em comparação com os livros didáticos usuais, propiciar melhor compreensão de certos conceitos e dos processos que envolvem a construção do conhecimento científico? Quais seriam as implicações da realização deste tipo de atividade para se estabelecer um ambiente no qual ocorra uma efetiva mediação dialógica entre o professor e os estudantes nas aulas? Seria esta uma estratégia adequada para abordar temas relacionados à história da ciência nas aulas? Tais questões constituem meus objetos de interesse no desenvolvimento da pesquisa ora apresentada. A investigação empírica é realizada propondo-se, aos alunos, um questionário sobre a leitura realizada, a ser respondido por escrito, e analisando-se qualitativamente as respostas dadas por eles. Adotando a premissa de que o conhecimento de elementos da história da ciência, através dos textos originais, pode constituir um valioso instrumento para a formação conceitual e crítica dos alunos com relação à prática científica (SILVA et al., 2008), iniciarei apresentando reflexões, baseadas em trabalhos reportados na literatura, que considero fundamentais para a temática da "utilização didática da história da ciência", expressão esta empregada por Peduzzi (2001, p. 151) e apropriada para a proposta deste estudo. Em seguida, descreverei sucintamente o referencial em que me apoio para analisar a produção dos estudantes, referencial este que propõe concepções sobre o ato de ler e a constituição de sentidos a partir da leitura. Passarei, então, à descrição das atividades realizadas e à análise dos relatos dos alunos.

\section{A história da ciência e o ensino de ciências}

Apesar de o ensino de ciências ter se desenvolvido por muito tempo quase que totalmente dissociado da história e da filosofia da ciência, é recorrente, nas propostas curriculares atuais de diversos países, a recomendação de que história, filosofia e sociologia (HFS) da ciência sejam incorporadas de forma mais abrangente nos programas dos cursos de ciências. No Brasil, os parâmetros curriculares nacionais do Ensino Médio (BRASIL, 2000) destacam que uma das contribuições esperadas da área de Ciências da Natureza, Matemática e suas Tecnologias é permitir ao estudante compreender a ciência como construção humana na qual estão presentes processos de acumulação de conhecimentos, continuidade e ruptura de paradigmas; bem como refletir sobre as implicações do desenvolvimento científico na sociedade em uma perspectiva que coloca a prática científica como uma prática social e cultural passível de influências econômicas e do contexto em que se insere.

Matthews (1995) aponta que, dentre as possíveis contribuições da HFS da ciência para o ensino de ciências, elas podem:

[...] humanizar as ciências e aproximá-las dos interesses pessoais, éticos, culturais e políticos da comunidade; tornar as aulas de ciências mais desafiadoras e reflexivas permitindo o desenvolvimento do pen- 
samento crítico; contribuir para a superação do "mar de falta de significação" que se diz ter inundado as aulas de ciências, onde fórmulas e equações são recitadas sem que muitos cheguem a saber o que significam; melhorar a formação do professor auxiliando o desenvolvimento de uma epistemologia da ciência mais rica e autêntica... (MATTHEWS, 1995, p. 165)

Este "mar de falta de significação", que Matthews (1995, p. 165) destaca em seu texto, é uma expressão adequada para retratar uma situação na qual o ensino de ciências, e mais especificamente da física, baseia-se quase que exclusivamente na resolução de exercícios e na apresentação, por vezes demais sucinta, dos conceitos, que logo são expressos na linguagem matemática sem que os alunos possam refletir sobre seus significados e atribuir sentidos que permitam compreendê-los. A inserção de aspectos históricos da construção conceitual pode propiciar esta oportunidade de reflexão e significação necessárias para a aprendizagem.

Segundo Castro e Carvalho (1995), assim como Könhlein e Peduzzi (2005), a ausência da dimensão histórica favorece uma visão distorcida da atividade científica, que pode levar o estudante a desenvolver uma imagem demasiadamente indutivista para a construção do conhecimento - menosprezando o papel das ideias e hipóteses, de teorias conflitantes, da epistemologia, dos dilemas éticos inerentes à produção da ciência e, até mesmo, das crenças metafísicas -, fazendo com que as grandes rupturas no conhecimento científico, em suas diversas áreas e em diferentes épocas, possam passar despercebidas, e que o aluno interprete a ciência como um produto acabado, fruto apenas da inspiração genial de poucos. A inserção de elementos de história da ciência possibilitaria, de acordo com Longhini e Nardi (2009), um resgate, ao menos, parcial do processo de produção do conhecimento vivido pelos cientistas em suas épocas.

A sugestão de um paralelismo entre o desenvolvimento cognitivo individual e o processo de desenvolvimento conceitual histórico encontra respaldo em relatos mostrando que as pessoas parecem ter uma capacidade de compreensão antecedente a qualquer ensino escolarizado, que, em certos aspectos, é similar às primeiras noções científicas ou pré-científicas (PEDUZZI; ZYLBERSZTAJN; MOREIRA, 1992; BARROS, 1998). A origem desta semelhança reside no fato de que as primeiras noções sobre fenômenos naturais e processos se basearam no senso comum, na realidade cotidiana, enquanto a ciência atual rompe com a experiência direta e sensorial ao se fundar nas idealizações e abstrações, que não são simplesmente apreendidas pela observação. Nesta perspectiva, o conhecimento de elementos de história da ciência poderia fornecer subsídios para o trabalho do professor frente a algumas concepções alternativas de seus alunos. Apoiando-se na obra de Bachelard, para quem a racionalidade do conhecimento científico é vista como uma ruptura radical com a racionalidade do senso comum, Lopes (1993, p. 327) afirma que "a dificuldade do aluno, muitas vezes, não é individual, fazendo parte de uma recorrência histórica”. E, por vezes, tais concepções alternativas ainda persistem após os alunos terem passado pelo ensino escolarizado das ciências, fruto, dentre outros fatores, de um ensino de ciências que as apresentam dogmatizadas e descontextualizadas de seus processos evolutivos (NEVES, 1998).

A inclusão de HFS da ciência nos cursos de formação de professores se torna interessante ao se considerar que, para explicar conceitos atuais ou por que determinada lei é válida 
em determinadas condições, é necessário conhecer algo sobre as relações entre a evidência e a teoria, papel esse que cabe à epistemologia. Ademais, não parece concebível que um bom professor de ciências não possua conhecimentos sólidos em relação a sua disciplina no que tange à terminologia por ela utilizada, aos seus objetivos por vezes conflitantes e ao seu caráter cultural e histórico. Conforme destacam Carvalho e Vannucchi (1996), grupos de trabalho em simpósios na década de 1990 já indicavam a relevância do tema para a formação do professor, tendo em vista proporcionar ao futuro docente:

1) uma maior compreensão da natureza do conhecimento científico; 2) um melhor entendimento dos conceitos e teorias da Física; 3) uma compreensão dos obstáculos e possíveis dificuldades dos alunos e 4) uma concepção das ciências como empresa coletiva e histórica e o entendimento das relações com a tecnologia, a cultura e a sociedade. (CARVALHO; VANNUCCHI, 1996, p. 7)

Em trabalhos recentes, Medeiros (2007) constatou equívocos sobre a relevância e a construção da escala de temperaturas Fahrenheit nas concepções de professores do Ensino Médio e licenciandos em física, enquanto Martins (2007) verificou que professores do Ensino Médio dificilmente incorporam o conhecimento histórico e filosófico sobre as ciências em suas práticas. Tais exemplos ilustram uma carência quanto à abordagem da dimensão histórica da ciência na formação de professores, seja na formação inicial ou continuada. Estes autores enfatizam que a superação de concepções ingênuas sobre a utilização da história da ciência passaria, dentre outros caminhos, pela produção de material didático de qualidade aliada a um mais sólido conhecimento do conteúdo histórico e epistemológico a ser trabalhado nos cursos de formação.

Mesmo sendo praticamente consensual que a utilização da história da ciência pode ser benéfica para o ensino das ciências, sua prática não está imune a equívocos e distorções. A inclusão de HFS da ciência em seu ensino é geralmente criticada por meio de dois argumentos principais: o primeiro afirma que a única história possível nos cursos de ciências é uma pseudo-história de má qualidade, com simplificações exageradas, erros e omissões que conduzem a uma falsificação da história, travestida de história verdadeira, argumento este reforçado também pela carência de materiais didáticos adequados sobre HFS da ciência; o segundo, construído a partir da análise de Kuhn (2009), sugere que a exposição à história da ciência enfraquece as convicções necessárias ao rápido e eficaz aprendizado da ciência normal e dos paradigmas vigentes, e que, preferencialmente, apenas cientistas já suficientemente experientes deveriam ter acesso à história.

Bastos (1998), ao descrever um trabalho de pesquisa no qual defende a viabilidade de utilização da HFS da ciência, enumera algumas outras dificuldades normalmente apontadas para o trabalho com HFS da ciência em sala de aula:

Os textos disponíveis para subsidiar o trabalho dos alunos em sala de aula dificilmente contemplam as necessidades específicas do ensino fundamental e médio; [...] há uma certa escassez de propostas concretas sobre como explorar conteúdos de História da Ciência de maneira a 
contribuir para a realização de objetivos educacionais como 'compreender melhor o que é a ciência' e 'formar o cidadão'; [...] os currículos escolares não dispõem de espaço suficiente para a uma adequada apresentação da História da Ciência; [...] os contextos específicos em que os cientistas do passado trabalhavam são de difícil compreensão para os alunos de hoje; [...] o uso de relatos históricos é fator de confusão e não de esclarecimento, pois expõe o aluno a idéias, problemas, conceitos, teorias e métodos que já foram descartados e substituídos por outros; [...] o uso de relatos históricos é fator de desmotivação e não de estímulo, pois o aluno está interessado em conhecimentos atualizados e não em conhecimentos que já caíram em desuso. (BASTOS, 1998, p. 56-57)

Todos esses argumentos são relevantes e devem ser ponderados, mas não invalidam, a priori, a presença da história nos cursos de ciências. Uma questão desafiadora que se coloca é: como incorporar HFS da ciência em seu ensino de modo a não apresentá-la como uma mera caricatura do processo histórico, ainda que recortes sejam necessários, e que possa contribuir efetivamente para o aprendizado dos estudantes? Para converter propostas curriculares em realidade, na sala de aula, são necessários, como enfatiza Matthews (1995): novos materiais didáticos, novas orientações para prática e avaliação, revisão dos conteúdos a serem trabalhados, e a inclusão de cursos adequados de formação dos professores enfocando tais propostas, cursos esses preferencialmente de natureza prática, que considerem problemas pertinentes à atividade docente. Mesmo sem uma estrutura como essa definida e instaurada, existem algumas possibilidades de inserção da HFS da ciência a serem consideradas. Uma delas é trabalhar com a leitura de textos sobre o assunto, podendo ser utilizados textos escritos por historiadores da ciência, por cientistas interessados em fazer divulgação do desenvolvimento de suas áreas de atuação, ou recorrendo-se a originais escritos por cientistas. O contato com originais pode propiciar novas formas de se pensarem as questões discutidas nos livros-texto convencionais, que, em geral, não apresentam a argumentação histórica da construção conceitual.

Matthews (1990) relata experiências de um curso de formação em HFS da ciência destinado a professores de ciências e baseado numa seleção de escritos de Galileu, Newton e Darwin, dentre outros, constatando que a maioria dos professores gostou da oportunidade de ler os trechos originais e que, até então, não haviam tido contato com esse tipo de material. No Brasil, Peduzzi (2001) explora a utilização didática da história da ciência em uma disciplina de Mecânica, em um curso universitário de física, utilizando um texto intitulado "Força e Movimento: de Thales a Galileu", e registrando o impacto positivo do texto junto aos alunos. Silva e Martins (2003) discutem uma possível abordagem histórica em física discutindo os experimentos de Newton e a construção de sua teoria sobre a composição cromática da luz branca, mas sem desenvolvê-la em condições de aula. Almeida (2004) trabalha a leitura de um texto original de Maxwell, no qual o autor comenta os métodos e as maneiras de apresentação dos resultados das pesquisas de Ampère e Faraday, por alunos do Ensino Médio e licenciandos de um curso de graduação em física, destacando as possibilidades de mediação em aula e a produção de sentidos advindas da atividade de leitura. Guerra et al. (2004) destacam uma aplicação de uma proposta curricular com caráter histórico para o ensino do eletromagnetismo no nível médio. 
Pena e Ribeiro Filho (2009) apontam que a abordagem histórica da construção do conhecimento científico de modo significativo, em situações de sala de aula, ainda requer mais experiências pedagógicas. Segundo estes autores, relativamente poucos relatos sobre tais experiências têm sido descritos e analisados na literatura especializada. Machado e Nardi (2006) também observam que, apesar de importantes para a compreensão da natureza da ciência, enfoques considerando a história da ciência têm estado pouco presentes nas atividades de ensino em seus diversos níveis. Assim, um dos objetivos deste trabalho passa a ser, também, colaborar para a reflexão sobre a inserção de elementos de história da ciência no ensino de física através da análise de uma atividade de leitura com alunos do primeiro ano de um curso Superior em ciência e tecnologia. Os textos disponibilizados para leitura consistem de trechos de originais de cientistas que contribuíram para o desenvolvimento da termodinâmica e da teoria cinética dos gases.

\section{Leitura e interpretação}

Ao se propor um trabalho com leitura de textos, cabe explicitar, ainda que brevemente, as concepções de leitura adotadas e em que aspectos este entendimento do ato de ler pode contribuir para as relações de ensino e aprendizagem. Segundo uma vertente francesa da análise de discurso (ORLANDI, 2007), considero a leitura de textos como produção e atribuição de sentidos, e não um mero processo de decodificação. Isto não exclui a possibilidade de a leitura constituir, também, um meio de transmissão de informações e de comunicação, mas a ênfase do estudo aqui realizado será sobre a produção de sentidos a partir da leitura dos textos originais.

Em conformidade com Orlandi (2007), os sentidos são produzidos em determinadas condições, que incluem: o texto, o leitor, a situação específica em que ocorre a leitura e o contexto histórico-social mais amplo em que o sujeito se insere. Nesta perspectiva, as condições da atividade proposta pelo professor se caracterizam como condições de produção nas quais os sentidos podem se constituir; condições que incluem, na realização desta atividade, a oportunidade de o aluno formular comentários, expressar suas dúvidas e responder a questões abertas.

E não há produção de sentidos sem interpretação, sem que o indivíduo se remeta à sua memória discursiva: um "já dito" anterior que suporta o próximo dizer; uma relação com a memória para que se originem novas significações. Adotar este referencial implica reconhecer a não-transparência da linguagem, que, conforme Almeida (2006), consiste, essencialmente, em notar que "no que se diz, no que se ouve, no que se escreve e no que se lê sempre há interpretação, ainda que os sentidos não possam ser quaisquer uns" (ALMEIDA, 2006, p. 63). Esta afirmação se insere no contexto do trabalho de Orlandi (1988), que assume uma perspectiva para a leitura baseada nas seguintes premissas:

a) Pensar a produção da leitura e, logo, a possibilidade de encará-la como possível de ser trabalhada (se não ensinada);

b) a leitura, tanto quanto a escrita, faz parte do processo de instauração de sentidos; 
c) o sujeito-leitor tem suas especificidades e sua história;

d) tanto o sujeito quanto os sentidos são determinados histórica e ideologicamente;

e) há múltiplos e variados modos de leitura;

f) nossa vida intelectual está intimamente relacionada aos modos e efeitos de leitura de cada época e segmento social. (ORLANDI, 1988, p. 8)

Assim, um dos ideais da educação escolar em qualquer nível seria propiciar, ao estudante, um trabalho no espaço da interpretação, com suas filiações de sentidos, e que estimule a produção de novos significados. Espero identificar, nos relatos dos alunos, indícios da construção de novos sentidos para os temas abordados nos textos, e que estes sentidos contribuam para a melhor compreensão dos conceitos envolvidos e do processo de evolução do conhecimento científico.

\section{Metodologia}

A atividade de leitura foi proposta, durante o mês de novembro de 2007, para 63 alunos do primeiro ano de graduação, matriculados na disciplina Fenômenos Térmicos, na Universidade Federal do ABC, em Santo André, SP. A disciplina é cursada por estudantes que se encontram normalmente no ciclo de disciplinas obrigatórias do Bacharelado em Ciência e Tecnologia e que poderão, futuramente, optar, ainda na graduação, por: física, química, matemática, computação, biologia, quatro modalidades de licenciatura ou uma das oito modalidades de engenharia oferecidas. Na ocasião, eu era o professor regular da turma e isto constituiu um elemento facilitador para o desenvolvimento desta pesquisa.

Foram selecionados seis textos escritos por cientistas renomados nas áreas de termodinâmica e teoria cinética, de modo a cobrir alguns dos principais tópicos estudados na referida disciplina. Os textos, extraídos do livro de Magie (1935) e considerados, por ele, de importância histórica para o desenvolvimento da física, foram traduzidos do inglês para o português a fim de possibilitar a leitura por vários alunos que ainda não possuíam familiaridade com a língua inglesa. Antes do corpo principal de cada texto original, Magie (1935) coloca um parágrafo inicial situando a época em que o autor viveu, os locais onde trabalhou e suas principais contribuições à ciência. Os títulos dos textos e seus respectivos autores são os seguintes:

Texto A: A Expansão dos Gases pelo Calor - Gay-Lussac

Texto B: O Poder Motriz do Calor - Carnot

Texto C: Entropia e Probabilidade - Boltzmann

Texto D: A Escala Fahrenheit - Fahrenheit

Texto E: Calor Latente - Black

Texto F: A Distribuição das Velocidades Moleculares - Maxwell

Estes textos não empregam a linguagem matemática na discussão dos temas. Neles, os autores descrevem e analisam suas hipóteses teóricas e resultados experimentais, fornecendo indícios dos caminhos trilhados para a construção dos conceitos associados à temática. Uma vez que os conceitos tratados nos textos são abordados nas disciplinas introdutórias de física e química no Ensino Superior, considerei interessante trabalhar os textos com alunos do 
primeiro ano, no momento em que tomam contato com esses conceitos pela primeira vez, ao menos no âmbito de suas formações acadêmicas na referida universidade.

Cada aluno recebeu três textos para leitura com as seguintes instruções:

Para cada um dos textos que você recebeu e leu, responda às seguintes questões:

1. O que você entendeu desse texto?

2. O que você achou do texto? Foi uma leitura fácil ou difícil? Em comparação com os livros didáticos através dos quais você estuda, você achou o texto mais interessante? Justifique.

3. Você acha que esse texto pode contribuir para o entendimento do conteúdo que está sendo estudado na disciplina? Em caso afirmativo, em quais aspectos?

4. Escreva suas dúvidas, aquilo que você não entendeu ao ler o texto. Há alguma coisa a mais que você gostaria de saber sobre o assunto e que o texto não detalha ou não explica $o$ suficiente?

Em termos gerais, responda também:

5. Você teria interesse em ler outros textos escritos por cientistas? Em caso afirmativo, sobre quais assuntos?

6. Você acha que a inserção de tópicos de história das ciências nas disciplinas que estuda seria interessante? Justifique.

Tais questões abertas foram formuladas tendo em vista os objetos de interesse na investigação apontados na introdução do presente trabalho e considerando-se a relevância das informações que os textos veiculam no âmbito da disciplina que os alunos estavam cursando. Além disso, a expectativa é que as leituras e a posterior resposta às questões propiciem aos estudantes uma reflexão acerca de como obterem informações a partir do texto e a oportunidade de expressarem suas impressões sobre o material lido. A estratégia de solicitar que os alunos respondam por escrito às questões propostas se fundamenta na premissa de que a escrita é uma atividade privilegiada quando se busca estimular as relações dos estudantes com seus saberes e interesses, com o texto exercendo função mediadora para o estabelecimento de tais relações (ALMEIDA; SOUZA; SILVA, 2006).

Os estudantes dispuseram de quatro semanas para realizarem a leitura e responderem as questões sugeridas. Foi enfatizado que o objetivo não era discriminar respostas certas e erradas, bem como não se atribuiriam "notas" para a atividade que foi executada em horário extraclasse. $\mathrm{Na}$ data agendada, 55 alunos entregaram suas respostas, sendo que 27 deles trabalharam com os textos A, B e C e 28 com os textos D, E e F. Li e analisei os trabalhos entregues e, dentro de meu planejamento didático, discuti com os alunos em aula as dúvidas por eles levantadas em resposta à questão 4.

Esta atividade de leitura e a aula dialógica que se seguiu para discussão das dúvidas constituíram uma prática diferenciada em relação às demais aulas da disciplina. Integrante de um ciclo básico comum a todos os estudantes da universidade, com várias turmas simultâneas sob responsabilidade de diferentes docentes, a disciplina Fenômenos Térmicos foi estruturada com uma mesma bibliografia recomendada, composta por livros tradicionais de física básica, como o de Halliday, Resnick e Walker (2006), e as mesmas listas de exercícios e instrumentos de avaliação para todas as turmas. Desse modo, não foi possível trabalhar a disciplina toda 
com o enfoque histórico, mas tornou-se viável a inserção destes elementos da história por meio dos textos originais selecionados.

O referencial teórico utilizado na análise dos dados coletados é a análise de discurso em sua linha francesa, desenvolvida por Pêcheux (apud ORLANDI, 2007) e difundida no Brasil por Orlandi (2007). Trata-se de um referencial interessante para a proposta desta pesquisa em função da importância conferida às condições de produção e aos sentidos atribuídos na leitura.

\section{Resultados e análise do material produzido pelos estudantes}

Cada subitem a seguir corresponde a um aspecto qualitativo que fornece subsídios para as questões colocadas como objetivos da pesquisa. Seleciono uma ampla variedade de sentidos manifestos pela diversidade de colocações dos alunos, transcrevendo trechos de suas respostas, mantendo a grafia original das mesmas, permitindo-me alguns recortes e preservando o anonimato de seus autores.

\section{Posicionamentos sobre a inserção da história da ciência na disciplina}

Quando da realização de uma nova atividade didática, é interessante tentar avaliar a receptividade dos alunos à proposta. Neste caso, é pertinente verificar como os estudantes se posicionaram com relação ao trabalho com os textos originais e, de modo mais amplo, o que pensam a respeito da inserção de elementos da história da ciência nas disciplinas que cursam. As questões 5 e 6 se destinaram a este propósito.

Dos 55 alunos que entregaram o questionário respondido, apenas um afirmou que não considera interessante a inclusão de história da ciência nos cursos, enquanto outro afirmou não ter interesse em ler textos escritos por cientistas.

\section{"Os alunos devem buscar tópicos de história da ciência por conta própria, não deve ser forçado". (Ro) \\ "Não tenho interesse em ler outros textos escritos por cientistas". (Do)}

A resposta de Ro parece revelar um perfil de aluno que teve poucas oportunidades para buscar assuntos de seu interesse em sua vida escolar, tendo sempre que passar por atividades impostas e, neste sentido, a inclusão de um novo tema de trabalho seria apenas mais uma obrigação. Talvez, permeando seu imaginário esteja um ideal de ensino que permita maior liberdade para o estudante, com possibilidade de encontrar objetos de estudo que lhe sejam mais significativos e interessantes.

Todos os demais alunos posicionaram-se favoráveis ao trabalho com a história da ciência e demonstraram interesse em ler originais de cientistas sobre os mais diversos assuntos. Isto reflete a variedade de preferências e possíveis afinidades da turma, que, cabe ressaltar, era bastante heterogênea quanto às pretensões de curso após o ciclo comum. Vale lembrar que a turma era constituída por futuros engenheiros, físicos, biólogos, químicos, professores e cientistas da computação. 
"Gostaria de ter mais acesso à história que envolve as teorias como por exemplo possiveis debates entre cientistas com teorias divergentes". (Ce)

"Sim, em especial na área energética, sobre fontes alternativas de energia e também na área de nanotecnologia". (Ca)

"Sim, sobre evolução, genética (principalmente doenças)". (La)

Sobre a inserção da história da ciência, seleciono algumas respostas dos alunos para análise de aspectos manifestados que considero relevantes.

"A ausência de tópicos de história da ciência pode bloquear, de certa forma, a capacidade de imaginação dos novos cientistas". (Le)

"Tópicos de história da ciência mostram a dificuldade e a criatividade dos cientistas na época em que viveram incentivando assim nossos estudos". (Pr)

Nas respostas de Le e Pr nota-se uma concepção segundo a qual conhecer um pouco sobre como os cientistas pensaram a respeito dos problemas que procuravam resolver pode ajudar o aluno a desenvolver sua capacidade criativa. O conhecimento das dificuldades dos cientistas frente às suas questões pode gerar uma identificação por parte dos alunos diante das dificuldades que encontram em seu aprendizado. Saber como conceitos foram formulados e soluções foram encontradas estimulariam as próprias construções de significados. Além disso, Le sugere que a ausência da contextualização histórica, mostrando uma ciência estritamente dogmática e com resultados prontos, prejudicaria o desenvolvimento de uma postura criativa dos novos cientistas.

Para Rd, o contexto histórico auxilia a atribuição de sentidos aos conteúdos, tornando-os mais compreensíveis.

"Sim, parece que consigo recordar melhor a matéria e discorrer melhor sobre ela quando situada num contexto bistórico". (Rd)

No discurso de Ka, evidencia-se a noção de que aprender determinado assunto em ciências, mais especificamente nas chamadas ciências exatas, não significa somente saber fazer cálculos, havendo outras possibilidades de abordagens.

"Sim, para o aprendizado não se limitar apenas a cálculos". (Ka)

Apesar de achar a história da ciência interessante, $\mathrm{Rg}$ faz a ressalva de que aulas de exercícios seriam mais eficientes para o aprendizado, colocando o enfoque histórico como apenas uma curiosidade. 
Leitura de textos originais de cientistas ...

"Embora seja interessante, creio que não contribuiria no entendimento do conteúdo da disciplina. Uma aula de exercícios sobre os conceitos vistos na disciplina seria muito mais produtivo na minha opinião". (Rg)

Provavelmente, este posicionamento advém de uma formação escolar pautada nas tradicionais aulas expositivas com resolução de exercícios, de modo que uma estratégia diferente causaria certa estranheza, uma percepção de uma aula ineficaz. Além disso, da maneira como os livros didáticos usuais apresentam a história, a mesma parece não passar de mera curiosidade, sendo relegada, quando presente, a notas de rodapé ou "boxes" à parte do corpo principal do texto e desvinculadas da abordagem dos conteúdos.

O aluno Je transparece certa preocupação com a possibilidade de os elementos históricos dificultarem a compreensão dos temas abordados. De fato, trabalhar com a história da ciência não se traduzirá necessariamente em uma maior facilidade de compreensão, mas poderá propiciar novas perspectivas para as relações de ensino e aprendizagem que farão com que a mediação do professor seja fundamental.

"Sim, seria interessante relacionar textos de cientistas como Einstein com a matéria estudada, mas desde que ele venha a proporcionar um melhor entendimento dela e não o contrário". (Je)

\section{As dúvidas e possibilidades de mediação}

Nas disciplinas introdutórias de física, nos cursos superiores, não é frequente o trabalho dos professores seguir uma abordagem dialógica reflexiva. O elevado número de alunos nas turmas e a necessidade de se cumprirem conteúdos programáticos extensos em relação à carga horária das disciplinas são fatores que contribuem para uma tendência de aulas predominantemente expositivas, nas quais, geralmente, os alunos não têm tempo para elaborarem suas dúvidas refletindo sobre o que acaba de ser exposto.

O registro por escrito permite que os estudantes expressem suas dúvidas após terem tempo hábil para uma mínima reflexão sobre o conteúdo apresentado, tornando possível o estabelecimento de um ambiente de mediação útil para o professor que se propõe a abordar adequadamente tais questionamentos formulados. Este foi o objetivo da quarta questão. A importância do papel mediador do professor nesta atividade de leitura de originais é ilustrada pelo relato do aluno Gr, que, inclusive, sugere uma estratégia alternativa para o trabalho com os textos originais:

"Gostaria de ler textos escritos por cientistas porém preferia ler esses textos com explicações e comentários de um professor". (Gr)

A respeito do texto $\mathbf{A}$, as dúvidas recaíram sobre o conceito de calórico, a visualização da montagem dos experimentos descritos e o fato de que, na época de Gay-Lussac (1935), ainda não se compreendia exatamente a natureza da grandeza medida pelo termômetro. 
"Não entendi o que são 'tensões de calórico". (Fe)

"Não entendi exatamente como é realizado o experimento do globo". (Ka)

"Gostaria de saber porque os cientistas não confiavam nos termômetros da época, quais eram as limitações deste aparelho e como era fisicamente". (Gr)

"A dúvida está no ponto em que é falado que não se sabe a taxa existente entre os graus do termômetro e a quantidade de calor que podem indicar". (Ta)

A leitura do texto $\mathbf{B}$ parece ter despertado mais curiosidades que vão além do texto do que dúvidas específicas sobre seu conteúdo, apesar de, novamente, o calórico e a dificuldade de visualização do aparato analisado por Carnot (1935) terem sido citados.

"A utilização do calórico traz um pouco de confusão. Qual a diferença de tomar o calor, nesse caso de Carnot, como matéria ou deixá-lo como o conbecemos? (Ti)

"Gostaria de saber se Carnot fabricava motores ou apenas os estudava". (Ga)

"Gostaria de saber com mais detalhes como funciona uma máquina térmica, em especial motor de avião e de carro". (Ro)

"Não consegui visualizar o funcionamento das máquinas a vapor". (Ar)

O texto $\mathbf{C}$ se caracterizou como grande gerador de dúvidas, em parte devido ao caráter abstrato do tema tratado por Boltzmann (1935). A interpretação microscópica da entropia e sua relação com o conceito de probabilidade é de difícil elaboração mesmo para alunos mais avançados nos estudos de física.

"Não entendi bem quando Boltrmann se refere a um "estado uniforme" do gás, não sei se está se referindo ao comportamento das moléculas ou a qualquer outro que eu não conheça”. (Rd)

"Qual seria o estado mais provável? Como o sistema fazpara atingi-lo? (Ti)

'Não ficou claro a relação entre entropia e probabilidade. Há uma relação matemática entre elas? (Je)

Sobre o texto $\mathbf{D}$, a maioria dos estudantes não apontou dúvidas, mas a atribuição dos valores à escala de temperatura Fahrenheit motivou questionamentos, como o de Fa. Detalhes sobre a construção do termômetro também geraram curiosidades.

"[...] O que eu não entendi do texto foi porque ele usou a temperatura de $48^{\circ}$ e os graus de comparação dele entre a temperatura mais alta e a mais baixa [...]”. (Fa) 
Leitura de textos originais de cientistas ...

"Seria interessante saber como é construido um termômetro". (Ed)

Questões interessantes foram levantadas a partir da leitura do texto E, no qual Black (1935) argumenta em favor de sua hipótese a respeito da absorção de calor durante a fusão de uma substância.

"Se for no contexto bistórico, creio que deveriam mostrar a reação da comunidade cientifica, se aceitaram sua teoria de inicio, ou se houve alguma contra-teoria, no demais foi fácil o entendimento”. (Lu)

"[...] gostaria de saber como esse calor que não pode ser medido por meio de um termômetro é medido durante a fluidez”. (Fa)

"Poderia ser descrito como Black chegou às fórmulas físicas, após concluir mentalmente sobre a existência de calor latente”. (DaR)

Assim como o texto C, o texto F, onde Maxwell (1935) apresenta hipóteses sobre a constituição dos gases na elaboração da teoria cinética, gerou diversas dúvidas, caracterizando-se como um texto cujo conteúdo foi de difícil entendimento para seus leitores.

'[...] não entendi, principalmente, a parte em que o autor interpreta as particulas como centros de força cuja ação é insensivel exceto quando as partículas se encontram a pequenas distâncias entre si, quando repentinamente ela se manifesta como uma força repulsiva de grande intensidade. Eu realmente não consegui esquematizar essa situação". (Br)

'Primeiramente, en gostaria de saber se já foi provada, em meios práticos, a proposta de Clausius, que determinou o comprimento médio do caminho em termos de distância média entre duas particulas e da distância entre o centro de duas particulas quando ocorre uma colisão (linhas 9, 10 e 11) pois até a época de Maxwell não havia sido provada em meios práticos. Outra dúvida é a explicação (molecular) dos fenômenos: condução de calor através de um gás e difusão de um gás através de outro". (Bu)

As dúvidas colocadas pelos estudantes podem ter sido propostas apenas com o intuito de mostrar ao professor que os textos foram lidos, mas também podem indicar um possível desejo de aprofundamento e esclarecimento por quem as formulou. A riqueza das dúvidas reveladas, em termos da profundidade dos questionamentos e da variedade de temas surgidos, evidencia um efetivo trabalho de interpretação com os textos; uma leitura na qual se procurou estabelecer relações de sentido para a compreensão dos conteúdos, em um processo que, por vezes, se deparou com obstáculos. Auxiliar os alunos na tentativa de superação destas dificuldades identificadas constitui uma das principais tarefas do trabalho educativo do professor, entendido como mediador do processo de construção do conhecimento por parte do aluno. Em meu planejamento didático, dediquei uma aula para discutir especificamente as dúvidas 
apontadas na atividade. Outra possibilidade seria respondê-las na medida em que se avança nos tópicos da disciplina, incorporando os questionamentos na preparação das aulas.

\section{Sobre a compreensão dos conceitos tratados nos textos}

A primeira questão solicitava aos alunos escreverem o que entenderam a respeito de cada texto lido, enquanto a terceira questão convidava a uma reflexão sobre possíveis contribuições dos textos para a compreensão dos assuntos abordados na disciplina. Analisando as respostas dadas a estas questões, é possível observar indícios de que as mesmas revelam as partes do texto nas quais os estudantes teriam produzido sentidos mais significativos, explicitando o entendimento que tiveram de certos conceitos abordados que lhes chamaram mais atenção. Nos enunciados estão implícitas relações entre os conteúdos dos textos e o que eles já sabiam ou julgavam saber sobre tais assuntos, sendo que essa interação histórica é constitutiva dos discursos produzidos.

No texto A, um dos pontos mais citados pelos alunos é o alerta que Gay-Lussac (1935) faz sobre uma importante causa de erros nas medidas da expansão volumétrica dos gases, identificada como a presença de água nos instrumentos.

"Nesse texto, Gay-Lussac fala sobre a expansão dos gases e vapores. Sen objetivo era confirmar que com um aumento fixo de temperatura, a expansão dos gases é a mesma. Ele cita previamente que essa determinação pode ser incerta devido a presença de água. Gay-Lussac fez, vários experimentos, a mesma temperatura e pressão, com vários gases. Com isso concluiu que todos os gases se expandem igualmente entre os mesmos graus de calor, ou seja, o experimento mostra que a expansão dos gases não depende da natureza particular dele”. (Je)

Em seu discurso, Ti destaca a importância da pesquisa acerca do fenômeno da expansão dos gases para outras áreas da ciência, conforme Gay-Lussac (1935) ressalta no início do texto, relacionando seu trabalho com problemas tecnológicos relevantes da época.

"O cientista pôde verificar que a expansão dos gases é igual, independente da espécie que está sendo verificada e que o vapor d'água pode atrapalhar a determinação da expansão. Diversas áreas da ciência dependem dos resultados dessa relação de expansão e calor, como a meteorologia, a astronomia, a quimica e a física". (Ti)

Segundo os alunos, a maior contribuição deste texto é a descrição feita pelo cientista de sua metodologia, indicando como as conclusões foram obtidas a partir dos experimentos.

"Agora nunca von esquecer do que trata a lei de Gay-Lussac, pois sei como que ele chegou nesses resultados". (Ro)

Apenas um estudante afirmou que o texto não contribui diretamente. 
"Para compreensão deste tópico estudado este texto não apresenta um valor significativo por apenas citar os experimentos. Porém é um bom texto para se ter noção sobre quais eram os problemas enfrentados pelos cientistas na época”. (Ga)

No texto B, Carnot (1935) descreve a transferência de calor como princípio de funcionamento de uma máquina térmica, fazendo uso do conceito de calórico, ainda em voga naquele período. Tal conceito havia sido comentado em aula antes de os alunos lerem o texto, e pude observar que parte deles emprega o termo "calórico" em suas respostas, por vezes enfatizando que se trata de um conceito superado, enquanto outros o substituem diretamente pelo termo atual "calor". O princípio de funcionamento das máquinas térmicas, baseado nas trocas de calor entre a fonte quente e a fria, parece ter sido compreendido pelos estudantes.

"Entendi, apesar da constante referência ao conceito errôneo do calórico, que o princípio de funcionamento de uma máquina a vapor é resultado das constantes trocas de calor entre componentes quentes e frios, sendo o vapor o componente principal pela facilidade desse transporte". (Gr)

O texto $\mathbf{C}$ foi o que gerou maiores dificuldades para os alunos que trabalharam com ele. Algumas razões prováveis para isto podem ser identificadas. O conteúdo do texto é, de fato, bastante abstrato, na medida em que relaciona entropia e probabilidade na construção de uma interpretação microscópica para a entropia; Boltzmann (1935) utiliza uma linguagem mais técnica em comparação com os textos A e B, além de se reportar a conclusões estabelecidas em outros textos, dificultando a continuidade da leitura. Mesmo assim, os relatos analisados evidenciam que diversos alunos compreenderam aspectos fundamentais do texto e, apesar de algumas ressalvas, se registraram posições que o consideraram útil para a compreensão dos conceitos.

"A partir desse texto entende-se que as trocas de calor realizadas por corpos que constituem determinado sistema tendem a ocorrer de tal forma que sua entropia aumente, ou seja, esse sistema vai de um estado improvável para um mais provável. A probabilidade de que o estado torne-se uniforme ao longo do tempo é maior, devido ao fato de existirem mais estados uniformes do que não-uniformes”. (Ta)

"Podemos calcular o estado de equilibrio investigando a probabilidade dos diferentes estados possiveis do sistema ou seja, aquele estado cuja probabilidade é maior de aparecer, este é o estado de equilibrio. Podemos identificar a quantidade de entropia com a probabilidade do estado atual do sistema". (Je)

"Talvez o texto fosse interessante após uma aula teórica sobre o assunto, como complemento, mas não como base de conceito". (El)

No texto D, Fahrenheit (1935) escreve sobre sua intenção de construir um termômetro, enfatizando que, em diversas oportunidades, não obteve sucesso até utilizar o mercúrio 
como substância termométrica, também indicando como determinou os valores empregados em sua escala.

"Segundo Fabrenheit, o que o estimulou a construir um termômetro foi a descoberta de que a água evaporava em um grau fixo de calor, e após várias tentativas ele resolven usar o mercúrio na construção de sen termômetro. A idéia do uso do mercúrio foi eficaz e após certo tempo Fahrenbeit testou se outros líquidos também evaporavam em graus fixos de calor". (Al)

"[...] Como base de cálculo de futuras comparações, ele apresentou também, a densidade dos líquidos aos $48^{\circ}$ de calor, que era a temperatura intermediária no termômetro dele entre a temperatura mais baixa, obtida artificialmente com uma mistura de água, gelo e sal amoníaco ou sal comum e o limite da temperatura mais alta, que é a encontrada no sangue de um homem sadio". (MaJ)

Este texto foi considerado superficial, por alguns alunos, em termos do desenvolvimento dos conceitos e, por isso, não contribuiria significativamente para o aprendizado, como relata MaA:

"Eu acho que o texto pode contribuir ponco uma vez que o texto aborda superficialmente conceitos abordados na disciplina". (MaA)

No texto E, Black (1935) discute o conceito de calor latente envolvido em uma transição de fase, na qual há uma liberação ou absorção de calor que não envolve variações na temperatura mensuráveis pelo termômetro. As respostas dos alunos revelam indícios de que os argumentos de Black foram entendidos, e a maioria colocou que o texto contribuiria para o entendimento dos conceitos abordados no curso.

"Ele contestou a idéia de que um corpo não recebe mais calor do que aquele medido pelo aumento ou queda da temperatura indicada pelo termômetro. Black, muito cuidadoso com suas observacões, elaborou a teoria de que um corpo recebe on perde muito mais calor que um termômetro possa medir durantes as mudanças de fase desse corpo". (Ma)

Alguns apresentaram opinião contrária, como é o caso de DaR, achando o conteúdo do texto óbvio. Talvez esta opinião se deva ao fato de que, atualmente, a noção de calor latente seja ensinada na escola desde o nível Médio como uma constatação óbvia e direta.

"De um modo geral, não. O texto não nos fornece argumentos técnicos suficientes.

É uma visão que qualquer pessoa mais atenta poderia concluir". (DaR)

O texto $\mathbf{F}$ pertence a um momento histórico em que há um acirrado debate na comunidade científica sobre a aceitação da hipótese da constituição atômica da matéria. Os relatos 
analisados indicam que, possivelmente, foi o texto mais difícil para os alunos que o trabalharam. No entanto, a hipótese corpuscular sobre a constituição dos gases e algumas de suas implicações foi destacada nos discursos produzidos.

"Maxwell tenta explicar os movimentos das particulas de um gás com as hipóteses da mecânica (supondo um sistema de esferas). Como acontece no aperfeiçoamento das teorias, se as propriedades obtidas dessas hipóteses corresponderem as dos gases, o estudo da matéria estará caminhando em direção a um rumo mais preciso; caso contrário, não haverá correspondência entre as hipóteses dos dois sistemas".

Ed tenta relacionar ideias sobre a verificação de conjuntos de hipóteses, conforme Maxwell (1935) destaca no texto, afirmando que, se houver uma correspondência entre as previsões da teoria e as propriedades mensuráveis dos gases, as hipóteses estarão retratando aspectos do comportamento das partículas constituintes dos gases; caso contrário, não haverá correspondência.

Aqueles que não classificaram a leitura do texto como difícil e pouco compreensível indicam que o mesmo auxilia no entendimento das hipóteses da teoria cinética.

"Com certeza. [...] esse texto complementaria bipóteses de cálculos que tentam explicar as propriedades dos gases". (Ed)

Diante de um assunto que, a princípio, não lhe interessa, Vi se posiciona de modo a não considerar o texto útil, uma vez que o mesmo se revelou ser de difícil leitura.

'[...] como não gostei muito do texto $F$, por não tratar de um assunto de men interesse, não acho viável acrescentá-lo para o entendimento do conteúdo do curso, já que não é de fácil entendimento". (Vi)

Em que pesem as dúvidas apontadas anteriormente, a leitura dos textos contribuiu efetivamente para que novas significações fossem produzidas para conceitos abordados na disciplina.

\section{Concepções sobre a evolução do conhecimento científico}

A leitura dos originais pode subsidiar o desenvolvimento de concepções sobre a produção do conhecimento científico, de modo que procurei identificar indícios de tais concepções nos escritos dos alunos. Obviamente, estas concepções não são fruto somente da leitura realizada; há um imaginário prévio que permeia as colocações dos estudantes, além de se considerar que parte deles estava cursando simultaneamente uma disciplina que trata das bases epistemológicas da ciência. Isto ilustra como os discursos produzidos pelos indivíduos são condicionados por suas histórias. Ainda assim, é possível verificar alguns elementos presentes nos textos lidos que contribuem para a formação destas ideias e que se refletem nos enunciados produzidos pelos leitores. 
Pr afirma que a história da ciência, revelada por seus principais protagonistas,

"Não só torna mais interessante como humaniza a ciência, mostra como ela foi ou está sendo construida, desmistifica o cientista mostrando que ele é bumano como nós, mostra seu método e como ele chegou em suas descobertas". (Pr)

A influência das condições econômicas e sociais de cada época sobre o que se pesquisa e na motivação do cientista é mencionada por Ga. Apesar de não se poder negar certa satisfação pessoal no trabalho científico, há determinantes de naturezas diversas que direcionam os objetivos e os objetos da investigação científica.

'[...] esses tópicos remontam a situação econômica e social da época, a qual ajuda a compreender o porquê de tal teoria ou invento ser feito em tal época, mostra a motivação que o cientista tinha além de seu prazer pessoal em fazê-lo". (Ga)

A contraposição entre antigas e novas interpretações para certos conceitos ilustra o dinamismo da atividade científica; uma atividade viva, que se modifica e se corrige em seus fundamentos conceituais e metodologias de investigação experimentais.

"Acho que serve de exemplo de como as coisas eram entendidas antes, o que mudou, o que melhorou”. (Fe)

"Mediante o texto escrito por Fahrenheit pude perceber que na época na qual o texto foi escrito os métodos empíricos usados atualmente ainda não haviam sido desenvolvidos e, consequentemente, fenômenos que para nós hoje em dia, parecem ser corriqueiros, naquela época eram estímulos para pesquisas científicas”. (Al)

Conhecer a metodologia da investigação científica, trilhando, ao menos em parte, os caminhos que conduziram os cientistas para o estabelecimento dos resultados de suas pesquisas, pode tornar tais resultados mais significativos para quem os estuda, conforme relata Gr:

"Contribui com um aprendizado mais completo, pois o aluno pode entender como o cientista chegou ao resultado e assim aceitar melhor o resultado. Além do texto ser uma "aula prática" sobre o método científico". (Gr)

"[...] mostra o avanço da ciência e retrata toda uma mentalidade de uma época. [...] Ensinar uma pessoa a pensar é muito mais valioso do que simplesmente mostrar um resultado e fazê-la aceitá-lo”. (FeP)

Estes trechos transcritos de Gr e FeP fazem pensar em que medida um resultado transmitido passivamente, sem uma mínima contextualização e referência ao seu processo de construção, é de fato compreendido e consolidado como um aprendizado. Quando Gr coloca a expressão "aceitar melhor o resultado", pode-se depreender que, quando isto acontece, o tal 
resultado adquire uma significação efetiva para o aluno. Também alerta para uma situação, não tão incomum nas aulas, em que a fala do professor expondo resultados e conclusões, aparentemente óbvias para si, não encontra ressonância na estrutura cognitiva do estudante.

Mencionando o texto de Fahrenheit (1935), Br destaca o trecho em que o autor enfatiza as leituras que realizava dos trabalhos de outros pesquisadores. Isto contribui para a desmistificação da figura do cientista, popularizada por certos meios de divulgação, como sendo alguém movido apenas por sua inspiração genial.

"Ao meu ver o ponto principal desse texto, além da introdução à Termometria aos olhos de Fabrenheit, é que ele mostra que o próprio Fabrenheit se utilizava de literaturas de outros cientistas e pesquisadores a fim de desenvolver seus próprios estudos, o que possibilitou a ele o desenvolvimento de novos conceitos como, neste caso, a adoção do mercúrio como substância termométrica”. (Br)

Um momento de ruptura é ilustrado pelo texto de Black (1935), que contrapõe uma nova ideia, sobre a absorção de calor por uma substância que se torna fluida, à concepção vigente na época, sendo destacado na resposta de Ma:

"Na minha opinião, o texto fica bastante interessante por se tratar de um texto que mostra como um cientista corrigiu a teoria de vários. Acaba despertando mais interesse pela matéria”. (MaA)

Concatenar os diversos elementos revelados nas respostas dos alunos sobre noções acerca da evolução da ciência é uma tarefa que, quando realizada e mediada pelo professor, pode contribuir positivamente na formação de visões não distorcidas com relação ao processo de construção do conhecimento científico.

\section{Os textos originais e os manuais didáticos}

A segunda questão permite analisar como os estudantes se posicionaram comparando os textos originais lidos com os livros didáticos através dos quais geralmente estudam, revelando, também, suas impressões e eventuais dificuldades na leitura. Diversos alunos mencionaram que desenhos e esquemas facilitariam a leitura e o entendimento dos textos originais, recursos estes que são comuns nos livros didáticos. Por outro lado, o estilo narrativo dos autores destes textos originais, contando como pensavam e trabalhavam, enfatizando aspectos conceituais e metodológicos em linguagem comum ao invés do direto emprego da linguagem matemática, colaborou para o envolvimento dos alunos na leitura, propiciando aos mesmos um olhar diferenciado, uma nova perspectiva para os temas em estudo. E este seria um componente fundamental na prática docente: o professor atuar de modo a viabilizar diferentes oportunidades, através da diversificação de atividades, para o estudante descortinar novos horizontes, novas possibilidades de interpretação e significação.

O texto A foi considerado de fácil leitura, e o maior destaque nas respostas dadas diz respeito à descrição, feita pelo próprio cientista, de seus experimentos de forma mais detalhada que nos livros didáticos. 
"Esse texto acaba se tornando mais interessante que um livro didático pois mostra parte daquilo que motivou o cientista a estudar sobre o assunto e também por mostrar como ele chegou às conclusões, diferentemente dos livros didáticos que apenas "jogam" fórmulas e teorias sem o conceito por trás disso". (Je)

"O interessante do texto foi que o próprio autor parecia falar em tempo real com o leitor, o que torna a leitura mais agradável à medida que participamos da explicação". (Le)

No caso de Le, percebe-se que o estilo narrativo do texto o atraiu de tal maneira que o mesmo se sentiu participando da explicação, um agente ativo convidado a construir o conhecimento junto com o cientista.

"O texto pode sim contribuir no entendimento do conteúdo pois é uma leitura mais gostosa que a dos livros por não possuir fórmulas e diversas contas no meio do texto". (Lc)

No relato anterior, Lc cita que a não-presença da linguagem matemática facilitou sua leitura. Outros estudantes também fizeram colocações semelhantes. A utilização de textos escritos predominantemente em linguagem comum pode ser uma estratégia para se trabalhar aspectos conceituais das disciplinas e auxiliar a transição entre as linguagens comum e matemática, que constitui uma das dificuldades para a aprendizagem da física, mesmo nas disciplinas básicas no Ensino Superior.

Alguns alunos se posicionaram de modo a preferir o livro didático apesar de considerarem o texto original interessante, como é o caso de Fe. Para este aluno, estudar pelos livros didáticos resulta em um aprendizado eficiente. Ou seja, provavelmente é um aluno com bom desempenho nas avaliações a que é submetido e para quem a tríade tradicional aula expositiva/livro didático/listas de exercícios produz bons resultados.

"É um texto diferente do que estou acostumado a ler, mas interessante, porém os livros didáticos são mais eficientes para o aprendizado". (Fe)

O texto B também foi considerado de leitura fácil, porém os alunos colocaram opiniões divergentes quanto a considerá-lo mais interessante que o livro didático. Talvez por terem visto algo a respeito de máquinas térmicas em outras ocasiões, aparentemente alguns deles sabiam mais sobre o tema do que Carnot (1935) escreveu nesse trecho, fazendo com que considerassem o texto superficial.

"Sim, este texto é mais interessante porque ele explica o que ocorre em uma máquina térmica sem entrar com as formulações matemáticas que são jogadas muitas vezes em certos livros”. (Ga) 
Leitura de textos originais de cientistas ...

"O funcionamento da máquina é descrito com clareza. Esta leitura não foi tão agradável quanto a de um livro didático, pois o último conta com figuras que possibilitam uma melhor visualização do funcionamento da máquina”. (Gr)

"Achei o texto fácil. Não achei mais interessante que outros livros, pois o texto é superficial e usa o termo calórico que é obsoleto". (Ro)

Nas transcrições a seguir, evidenciam-se algumas dificuldades que o texto $\mathbf{C}$ apresentou para a leitura dos estudantes e, em vista de tais dificuldades, a maioria apontou o livro didático como sendo mais adequado para abordar este tema.

"É um texto de linguagem rebuscada que gera certa dificuldade na compreensão, mas que mesmo assim não perde a originalidade do pensamento de Boltrmann, sendo interessante ao demonstrar o que ele próprio pensava a respeito". (De)

"Não achei interessante justamente por não ter entendido. Acho que os livros didáticos costumam ser mais fáceis de entender e conseqüientemente mais interessantes, pois não há como se interessar por algo que não se entende". (Li)

Todos os alunos consideraram o texto $\mathbf{D}$ de fácil leitura e mais interessante do que os encontrados em livros didáticos. Argumentaram que a linguagem, até certo ponto informal, da narrativa, ao não se deter em conceitos e fórmulas, auxiliou na leitura, e que a visão do cientista é importante para que se entendam o contexto e os conceitos.

"Achei o texto uma leitura fácil, pois o mesmo se utiliza de uma linguagem comum $e$ de fácil entendimento. Em comparação com livros didáticos, achei a leitura mais agradável, uma vez que o enfoque parece mais ser de apresentar a maneira de pensar de um cientista e não somente relatar as conclusões e descobertas de forma técnica”. (FeP)

O texto $\mathbf{E}$ foi considerado de fácil entendimento pela maioria dos alunos. Apenas um deles relatou ter achado o texto difícil e, por isso, menos interessante que os livros didáticos.

"Na minha opinião, esse foi um texto bastante monótono e complexo, então achei que foi uma leitura difícil. Em comparação com os livros didáticos, não achei esse texto mais interessante". (FeK)

"O texto é bem esclarecedor quanto ao conceito de calor latente, demonstrando os fundamentos defendidos por Black em oposição às idéias que vigoravam na época. $O$ texto foi escrito numa linguagem simples e de fácil compreensão. O texto se mostra mais interessante que os livros didáticos pois o conceito de calor latente é explicado pelas próprias palavras de Black, dando uma maior credibilidade ao material estudado”. (Br) 
Vale salientar o poder que a fala do cientista exerce no imaginário do aluno $\mathrm{Br}$ e, provavelmente, no de muitas pessoas, quando este afirma que o conceito apresentado pelas palavras do próprio Black (1935) confere "maior credibilidade" ao assunto. É a imagem idealizada de autoridade que o aluno atribui ao cientista.

$\mathbf{O}$ texto $\mathbf{F}$ dividiu a opinião dos leitores.

"A leitura do texto foi de dificuldade moderada. A linguagem utilizada é muito simples, porém para explicar os fenômenos dos gases e as grandezas a se estudar é muito difícil, uma vez que envolvem muitos outros conceitos. Achei o texto interessante, uma vez que trata dos estudos e esforcos do cientista, mostrando a maneira do mesmo de pensar, ao invés de simplesmente relatar os resultados da pesquisa em um livro a fim de ensinar outros". (FeP)

"Em relação aos livros didáticos o texto não foi interessante, pois não apresentou uma conclusão”. (MaJ)

A opinião de MaJ revela certo desapontamento com o texto de Maxwell (1935), na medida em que nele o autor coloca as hipóteses da teoria cinética dos gases mas não apresenta resultados conclusivos, como provavelmente ela está habituada a encontrar nos livros que estuda.

Comentários gerais acerca do trabalho com os textos foram apresentados:

"Gostei muito dos três textos, pois os três foram originalmente escritos por Fahrenheit, Black e Maxwell, e não escritos sobre eles. Os três textos são de fácil entendimento e se comparados aos livros didáticos pelos quais estudo são mais interessantes porque mostram as concepcões das suas respectivas épocas. Entretanto, não são mais eficientes do que os livros didáticos pelos quais estudo, já que da época que foram escritos para cá houveram muitas inovações tecnológicas e cientificas que são necessárias para um conhecimento mais amplo das ciências”. (Al)

No relato de $\mathrm{Al}$ observa-se o argumento de que, apesar de interessantes, os textos históricos originais não seriam mais eficientes para o aprendizado devido às mudanças conceituais e tecnológicas que ocorreram da época em que foram escritos até o presente; ao passo que La, Pr e Ed argumentam em favor de uma articulação entre os diferentes tipos de texto no curso.

"Os três textos $(A, B$ e $C)$ são tão interessantes quanto aqueles dos livros didáticos; eles se complementam: os didáticos apresentam certos conceitos e definições que são fundamentais para a compreensão desses textos mais científicos. Assim é interessante que os dois tipos de texto se apresentem paralelamente: enquanto o texto didático fornece subsidios para podermos compreender textos cientificos, estes complementam e aprofundam o conteúdo de textos didáticos". (La)

1008

Ciência \&̊̊ Educação, v. 17, n. 4, p. 987-1013, 2011 
Leitura de textos originais de cientistas ...

"Acho interessante a leitura de ambos [texto e livro didático, nota do autor] pois faz um paralelo entre como o cientista chegou naquela conclusão e como hoje isso é estudado". (Pr)

"Em comparação com os livros didáticos pelos quais estudo, acho que um texto como esse têm a sua importância, e os textos dos livros também, e, acrescento, esse texto deveria ser incluso nos livros didáticos". (Ed)

Os textos originais mostram uma face da ciência que usualmente não está contida nos manuais didáticos; uma ciência em transformação, que evolui na construção de seus conceitos, humanizada e condicionada social e economicamente. Uma proposta pedagógica que considere uma articulação entre os textos originais e os manuais convencionais pode encontrar ressonância entre os alunos.

\section{Equívocos}

A atividade de leitura proposta com os originais - assim como quaisquer outras que procurem trabalhar no âmbito das interpretações dos alunos - não está imune a equívocos, sejam eles cometidos por falta de interesse e comprometimento com a atividade, ou por dificuldades efetivas na realização da mesma.

O relato a seguir revela a produção de um sentido interditado na leitura, pois quem o produziu repetiu o dizer de Gay-Lussac (1935, p.166) de que "ainda estamos longe de termos certos conhecimentos sobre a expansão dos gases", não atentando que essa fala do cientista é de cerca de 200 anos atrás e que, hoje, o fenômeno em questão é bem compreendido.

"Posso concluir que apesar de ainda estarmos muito longe de termos certos conhecimentos sobre a expansão dos gases, sabemos que todos eles possuem a mesma expansão entre os mesmos graus de calor contanto que eles estejam sob as mesmas condições". (Ka)

"Que Carnot, mesmo tendo a errônea idéia de calórico, introduziu o conceito de ciclos de operação, que é válido até hoje. A máquina mais eficiente possivel é aquela na qual todas as operações são reversivieis". (Ro)

A última frase da resposta de Ro sobre operações reversíveis e eficiência das máquinas térmicas não foi produzida apenas com base no texto de Carnot (1935), uma vez que o mesmo não faz menção explícita a esses pontos. Conhecimentos anteriores à leitura, ou buscados em outras fontes para realizar a tarefa, deviam fazer parte do imaginário do estudante ao responder o questionário.

Ga coloca que somente de posse de certos pré-requisitos poderia entender melhor o texto de Boltzmann (1935). Isto não necessariamente aconteceria. Apesar de possivelmente Ga achar que deveria entender o texto sozinho se tivesse estudado a segunda lei da termodinâmica anteriormente, talvez não pudesse prescindir da mediação do professor devido à natureza distinta do texto de Boltzmann em comparação com o do livro didático ao tratar do assunto. 
"Eu não compreendi bem, porque não estudei sobre a segunda lei da termodinâmica e entropia e para a compreensão do texto é necessário saber sobre esses tópicos". (Ga)

A maneira como MaA escreve deixa transparecer a ideia de que Fahrenheit (1935) não sabia o que estava fazendo. Talvez a maneira aparentemente honesta com que Fahrenheit descreve as dificuldades em seus estudos contraste de tal modo com a imagem que MaA tem do cientista como sendo infalível em sua área, que tenha motivado sua afirmação.

"Eu entendi que o Fahrenheit foi um cientista que apesar de não entender muito do assunto, não desistiu de realizar experimentos até obter resultados aceitáveis, $e$ que futuramente viriam a ser corretos". (MaA)

MaJ se equivoca em relação ao conteúdo do texto ao afirmar que Maxwell (1935) tentou determinar a distância média entre os centros de duas partículas em colisão.

"Maxwell, acompanhando os estudos de Bernoulli, Joule, Kronig, Clausius entre outros, sobre a velocidade, a temperatura, a pressão e a densidade em um gás perfeito, tentou através de princípios mecânicos a determinação da distância média entre os centros das duas partículas quando ocorre uma colisão suposta por Clausius, pois até então não haviam métodos para sua determinação”. (MaJ).

É sempre possível que os estudantes manifestem concepções relacionadas a saberes equivocados internalizados, procurando relacionar o conteúdo do texto com suas cotidianidades. Mas, apesar da leitura admitir uma variedade de sentidos, eles não podem ser quaisquer; as condições de leitura e produção de sentidos podem ser mediadas para que eventuais equívocos sejam retificados.

\section{Considerações finais}

Esta pesquisa empírica se insere no contexto das possibilidades de introduzir elementos de história da ciência em aulas de ciências nos diversos níveis de ensino. Foi realizada uma atividade de leitura de textos originais, seguida pela resposta por escrito a questões abertas propostas sobre os textos, com alunos do primeiro ano do Ensino Superior, em uma disciplina de física básica. Apesar de ser praticamente consensual entre pesquisadores da área a recomendação da inclusão da história da ciência nos cursos, os mesmos apontam a necessidade de mais experiências em situações de sala de aula, de modo que procurei contribuir para esta temática analisando qualitativamente os sentidos produzidos pelos estudantes a partir da leitura dos textos originais.

As respostas ao questionário revelam que os discursos elaborados pelos alunos foram bastante variados em relação aos possíveis sentidos atribuídos aos textos. Em alguns casos, os leitores se detiveram nos dizeres do texto; em outros, manifestaram suas opiniões. Posicionaram-se com julgamentos de valor, com críticas fundamentadas, emitiram dúvidas, interpreta- 
Leitura de textos originais de cientistas ...

ram e colocaram sugestões que, provavelmente, não seriam expressas sem essa oportunidade propiciada pela natureza atividade realizada. Puderam compreender certos conceitos a partir de uma perspectiva diferente, conforme a ótica dos próprios construtores destes conceitos, constituindo novas significações para os mesmos. Sentiram-se, na maioria das vezes, mais estimulados pela leitura dos originais em comparação com os manuais através dos quais estão habituados a estudar, e obtiveram novos elementos para a formação de suas concepções a respeito da evolução do conhecimento científico. E a viabilidade didática desta abordagem envolve o fundamental papel mediador do professor, tanto para tratar das dúvidas apontadas quanto das dificuldades de leitura e dos sentidos equivocados que surgem.

A aproximação com a história da ciência é evidenciada, no discurso dos alunos: pelo gosto que a maioria revelou em ler os originais, pelos indícios de uma melhor compreensão sobre a construção dos conceitos abordados, pela percepção de diferenças entre o conhecimento atual e o veiculado nos textos, que contribui para uma postura um pouco mais crítica em relação à evolução dos conceitos científicos, e pelos "fatos novos" que revelaram ter aprendido sobre os temas.

Ainda que não tenha sido possível desenvolver toda a disciplina com um enfoque histórico, a presença de elementos da história da física através dos textos originais constituiu uma estratégia viável para a abordagem do caráter histórico, indicando que, se bem articulada com o enfoque tradicional das aulas, a história da ciência contribui positivamente tanto para um ensino mais significativo culturalmente quanto para a formação científica específica dos estudantes.

\section{Referências}

ALMEIDA, M. J. P. M. Discursos da ciência e da escola: ideologia e leitura possíveis. Campinas: Mercado das Letras, 2004.

ALMEIDA, M. J. P. M.; SOUZA, S. C.; SILVA, H. C. Perguntas, respostas e comentários dos estudantes como estratégia na produção de sentidos em sala de aula. In: NARDI, R.; ALMEIDA, M. J. P. M. (Orgs.). Analogias, leituras e modelos no ensino da ciência: a sala de aula em estudo. São Paulo: Escrituras, 2006. p. 61-76.

BARROS, M. A.; CARVALHO A. M. P. A história da ciência iluminando o ensino de visão. Ciência \& Educação, Bauru, v. 5, n. 1, p. 83-94, 1998.

BASTOS, F. O ensino de conteúdos de história e filosofia da ciência. Ciência \& Educação, Bauru, v. 5, n. 1, p. 55-72, 1998. 
Zanotello, M.

BLACK, J. Latent heat. In: MAGIE, W. F. (Org.). A source book in Physics: heat. New York: McGraw-Hill, 1935. p. 139-142.

BOLTZMANN, L. Entropy and probability. In: MAGIE, W. F. (Org.). A source book in Physics: heat. New York: McGraw-Hill, 1935. p. 262-263.

BRASIL. Ministério da Educação. Parâmetros Curriculares Nacionais: Ensino Médio. Brasília: Secretaria de Educação Média e Tecnológica, 2000. Disponível em: <http:// portal.mec.gov.br/seb/arquivos/pdf/ciencian.pdf>. Acesso em: 7 ago. 2009.

CARNOT, N. L. S. The motive power of heat. In: MAGIE, W. F. (Org.). A source book in Physics: heat. New York: McGraw-Hill, 1935. p. 221-222.

CARVALHO, A. M. P.; VANNUCCHI, A. O currículo de física: inovações e tendências nos anos noventa. Investigações em Ensino de Ciências, Porto Alegre, v. 1, n. 1, p. 3-19, 1996.

CASTRO, R. S.; CARVALHO A. M. P. The historic approach in teaching: analysis of an experience. Science \& Education, Dordrecht, n. 4, n. 1, p. 65-85, 1995.

FAHRENHEIT, D. G. The Fahrenheit scale. In: MAGIE, W. F. (Org.). A source book in Physics: heat. New York: McGraw-Hill, 1935. p. 131-133.

GAY-LUSSAC, L. J. The expansion of gases by heat. In: MAGIE, W. F. (Org.). A source book in Physics: heat. New York: McGraw-Hill, 1935. p. 166-170.

GUERRA, A. et al. Uma abordagem histórico-filosófica para o eletromagnetismo no ensino médio. Caderno Brasileiro de Ensino de Física, Florianópolis, v. 21, n. 2, p. 224-248, 2004.

HALLIDAY, D; RESNICK, R.; WALKER, J. Fundamentos de física. 7. ed. Rio de Janeiro: LTC, 2006. v. 2.

KÖNHLEIN, J. F. K.; PEDUZZI, L. O. Q. Uma discussão sobre a natureza da ciência no ensino médio: um exemplo com a teoria da relatividade restrita. Caderno Brasileiro de Ensino de Física, Florianópolis, v. 22, n. 1, p. 36-70, 2005.

KUHN, T. S. A estrutura das revoluções científicas. 9. ed. São Paulo: Perspectiva, 2009. (Debates, 115).

LONGHINI, M. D.; NARDI, R. Como age a pressão atmosférica? Algumas situaçõesproblema tendo como base a história da ciência e pesquisas na área. Caderno Brasileiro de Ensino de Física, Florianópolis, v. 26, n. 1, p. 7-23, 2009.

LOPES, A. R. C. Contribuições de Gaston Bachelard ao ensino de ciências. Enseñanza de las Ciencias, Barcelona, v. 11, n. 3, p. 324-330, 1993.

MACHADO, D. I.; NARDI, R. Construção de conceitos de física moderna e sobre a natureza da ciência com o suporte da hipermídia. Revista Brasileira de Ensino de Física, São Paulo, v. 28, n. 4, p. 473-485, 2006.

MAGIE, W. F. A source book in Physics. New York: McGraw-Hill, 1935. 
Leitura de textos originais de cientistas ...

MARTINS, A. F. P. História e filosofia da ciência no ensino: há muitas pedras nesse caminho... Caderno Brasileiro de Ensino de Física, Florianópolis, v. 24, n. 1, p. 112-131, 2007.

MATTHEWS, M. R. História, filosofia e ensino de ciências: a tendência atual de reaproximação. Caderno Catarinense de Ensino de Física, Florianópolis, v. 12, n. 3, p. 164-214, 1995.

. History, philosophy and science teaching: what can be done in an undergraduate course? Studies in Philosophy and Education, Dordrecht, v. 10, n. 1, p. 93-98, 1990.

MAXWELL, J. C. The distribution of molecular velocities. In: MAGIE, W. F. (Org.). A source book in Physics: heat. New York: McGraw-Hill, 1935. p. 258-259.

MEDEIROS, A. O desenvolvimento histórico da escala Fahrenheit e o imaginário de professores e estudantes de física. Caderno Brasileiro de Ensino de Física, Florianópolis, v. 24, n. 2, p. 155-173, 2007.

NEVES, M. C. D. A história da ciência no ensino de física. Ciência \& Educação, Bauru, v. 5, n. 1, p. 73-81, 1998.

ORLANDI, E. Discurso e leitura. Campinas: Cortez; Editora da Unicamp, 1988.

Interpretação: autoria, leitura e efeitos do trabalho simbólico. 5. ed. Campinas:

Pontes, 2007.

PEDUZZI, L. O. Q. Sobre a utilização didática da história da ciência. In: PIETROCOLA, M. (Org). Ensino de física: conteúdo, metodologia e epistemologia numa concepção integradora. Florianópolis: Editora da UFSC, 2001. p. 151-170.

PEDUZZI, L. O. Q.; ZYLBERSZTAJN, A.; MOREIRA, M. A. As concepções espontâneas, a resolução de problemas e a história da ciência numa seqüência de conteúdos em mecânica: o referencial teórico e a receptividade de estudantes universitários à abordagem histórica da relação força e movimento. Revista Brasileira de Ensino de Física, São Paulo, v. 14, n. 4, p. 239-246, 1992.

PENA, F. L. A.; RIBEIRO FILHO, A. O uso didático da história da ciência após a implantação dos Parâmetros Curriculares Nacionais para o Ensino Médio (PCNEM): um estudo a partir de relatos publicados em periódicos nacionais especializados em ensino de física (2000-2006). Caderno Brasileiro de Ensino de Física, Florianópolis, v. 26, n. 1, p. 48-65, 2009.

SILVA, C. C.; MARTINS, R. A. A teoria das cores de Newton: um exemplo do uso da história da ciência em sala de aula. Ciência \& Educação, Bauru, v. 9, n. 1, p. 53-65, 2003.

SILVA, C. P. S. et al. Subsídios para o uso da história das ciências no ensino: exemplos extraídos das geociências. Ciência \& Educação, Bauru, v. 14, n. 3, p. 497-517, 2008.

Artigo recebido em 12/08/2010. Aceito em 20/01/2011. 